\title{
Welcome to Nordina!
}

As editors we are very happy to welcome you as a reader to our new Nordic journal of science education and hence to a pivotal point in the history of science education in a Nordic context. This point is important for several reasons. During the last decades science education has increasingly developed as an academic field of research in our countries. We now have departments at universities, professorships of science education and an increasing number of doctoral dissertations and research projects. People engaged in the field have published their work either in a purely national context or in international journals of science education or education more generally. While the former reaches out to a limited audience, the latter has required that we adjust to an international frame of reference where interesting aspects of the research context might be lost on the way. Although both these ways of publishing have their legitimacy, a Nordic journal will enable us to obtain the best from both of them; we can share our work with a larger audience but still be able to communicate within our specific cultural context.

Language is an important part of the cultural context. For many of us, Nordina provides opportunities to publish our work and to learn from each other in our own language, and still direct our writings further than to colleagues in our own country. The multilingual approach we have chosen for our journal is a kind of experiment. Since Nordina is a Nordic journal, we have chosen to publish articles in those Nordic languages that can be understood by neighbours; that is, Swedish, Danish and Norwegian. In order to include authors (and readers) from Iceland and Finland and others who prefer to present their work in English, we will also publish articles in English. This also opens up the possibility to reach out to an even larger international audience. For this first issue of Nordina, about half of the contributions are written in English while the reminders are in Nordic languages. We believe that this means that the 'experiment' has been fruitful, and hope that multilingual Nordina will work well for authors as well as readers in all the Nordic countries.

The need for a place to publish work at a scientific level is pressing and increasing for science educators as well as others employed in the academic world. Again, Nordina provides a place for us to publish with credibility. We see the credibility of the journal as extremely important. All submitted articles are reviewed by two independent referees as well as the editors to ensure high standards - yet without unnecessary standardization that limits creativity. What 'high standards' means is, however, a problematic field, and the issue has been subject to lively discussions between editors and referees. This will probably be an on-going process in defining and redefining the profile of Nordina in the future. We believe that there is always something to be learnt in this process, and that those of you accepting to review articles will also be rewarded along the way in terms of new reflections on what constitutes quality in our field.

In addition to articles following a scientific scheme, we also welcome shorter informative descriptions of major initiatives in science education, such as on-going projects and curriculum development. We also present recent doctoral and licentiate's dissertations in our field with a short 
abstract. Since this is the very first issue, we have chosen to stretch the concept 'recent' somewhat. In the present issue dissertations completed in 2003 are presented, while the next issue due in autumn 2005 will present those from 2004. In later issues we will hopefully be up-to-date with regards to what can be considered 'recent'. We regret that we have not been able to collect information on every single dissertation completed the last two years. Those that we have missed are, of course, welcome in later issues.

The idea of a Nordic journal has existed for many years, but first became concrete at a meeting in Göteborg early summer 2004. Without not really knowing where we were heading, we decided to establish the journal, that its name is Nordina and that the first issue was to be published spring 2005. These months have been an exciting and at times painstaking journey towards completion of this first issue of Nordina. The response to call for contributions confirmed to us that Nordina fulfilled a real need. Many responded with enthusiasm that they would submit articles to Nordina; not everyone has done so thus far, but your articles are certainly welcome in subsequent issues. What is absolutely clear is that a journal cannot exist without authors. So the destiny of Nordina is in the hands of all of you; send us articles!

Nordina's existence is also dependent on other actors. To keep to a high standard, we depend on all of you being willing to review papers. We are well aware that this comes in addition to other pressing work duties, but we have nonetheless experienced a high degree of commitment from those of you having reviewed papers for us thus far. We thank every one of you warmly for the job you have done. In order to ensure the anonymity of referees, we have decided not to list their names in each issue, but rather to present them collectively year-by-year.

A journal in paper format also needs a good layout. In this regard we have received useful help from Irene Haldorsen Enne at the Information Department, University of Oslo, who worked out a layout outline for us based on some very vaguely expressed ideas. Next, Lise Faafeng at the Norwegian Centre for Science Education has had the considerable job of adjusting this layout to our constantly changing needs, and getting everything in place within a limited amount of time but with a great deal of hard work and enthusiasm.

Finally, no matter how idealistic our work with Nordina is, it does indeed have an economic side. The high quality of the material appearance, and the distribution of it, has its costs. In this regard we are grateful to Anders Isnes, leader of the Norwegian Centre for Science Education, for willing to spend a significant amount of money from the Centre in order to realize the first issue of Nordina. While paper prints and distribution cost money, web publishing is in principle free. In the future, we will need to consider web publishing exclusively. We do, however, believe that good old paper still plays a role that the web cannot, at least in establishing a new journal. In the meantime, we consider a parallel publication of articles on our web site www.naturfagsenteret. no/tidsskrift/nordina.

Finally, we thank everyone again for their contributions to this historical issue, and express the hope that Nordina will contribute to further the development of science education, and to strengthen the contact between colleagues in neighbouring countries.

Greetings from the editors,

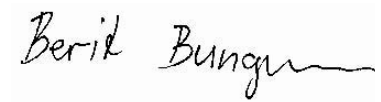

Berit Bungum

University of Oslo

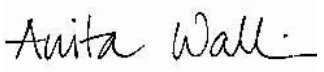

Anita Wallin

Göteborg University

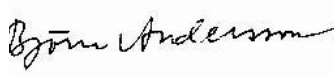

Björn Andersson Göteborg University 